\title{
OPTIMIZATION OF PRODUCTION PROCESSES USING THE YAMAZUMI METHOD
}

\author{
Dušan Sabadka', Vieroslav Molnár², Gabriel Fedorko², Tomasz Jachowicz ${ }^{3}$ \\ 1 Technical University of Kosice, Faculty of Mechanical Engineering, Department of Automotive Production, \\ Mäsiarska 74, 04001 Kosice, Slovak Republic, e-mail: dusan.sabadka@tuke.sk \\ 2 Technical University of Kosice, Letna 9, 04200 Kosice, Slovak Republic, e-mail: gabriel.fedorko@tuke.sk; \\ vieroslav.molnar@tuke.sk \\ ${ }^{3}$ Lublin University of Technology, Faculty of Mechanical Engineering, Department of Polymer Processing, \\ Nadbystrzycka 36 St., 20-618 Lublin, Poland, e-mail: t.jachowicz@pollub.pl
}

Received: 2017.09.25

Accepted: 2017.11.01

Published: 2017.12.05

\begin{abstract}
Manufacturing companies are now placing great emphasis on competitiveness and looking for ways to utilise their resources more efficiently. This paper presents optimum efficiency improvement of the automotive transmission assembly production line by using line balancing. 3 assembly stations were selected to optimize where waste management requirements are not met for achieving the production capacity. Several measures were proposed on the assembly lines concerned to reduce operations by using eliminating unnecessary activities of the assembly processes, reducing the cycle time, and balancing manpower workload using line balancing through Yamazumi chart and Takt time. The results of the proposed measures were compared with the current situation in terms of increasing the efficiency of the production line.
\end{abstract}

Keywords: lean manufacturing, bottlenecks, Yamazumi chart.

\section{INTRODUCTION}

Lean manufacturing is the technique of production control for eliminating the waste from the manufacturing process. Lean manufacturing also focuses on cost reduction through eliminating unnecessary activity by applying management philosophy which focused on identifying and eliminating waste from each steps in the production chain [1].

Benefits of lean manufacturing are reduced inventory, less process waste, less rework, reduced lead time, financial saving and increase process understanding [2].

In order to obtain the maximum production, a company must manage the production line by a systematic techniques or approaches. One of the techniques is line balancing technique. The use of line balancing technique was proved able to increase the productivity of the company.
Acording to Becker and Scholl [3] an assembly line is a cycle of workstations at which tasks related to assembly of a product are performed. Agpak and Gokcen state in their publication [4] that the common objective for assembly line balancing is to minimize the number of work-stations for a given cycle time and minimize cycle time for a given number of work stations.

\section{METHODOLOGY}

Cycle time is defined as the time it takes to do a process [5]. It includes the time from when an operator starts a process until the work is ready to be passed on. Yamazumi chart is used as a tool to proceed Kaizen for line balancing [6, 7]. Yamazumi chart is a bar chart that shows the total cycle time for each operator when performing their process in the production flow. 


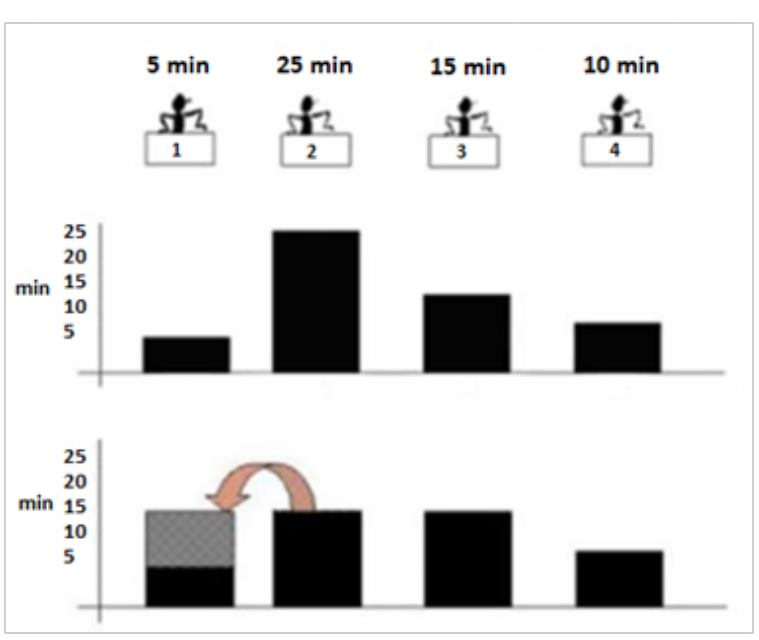

Fig. 1. Method of moving installation [8]

The assembly lines contain boards where Yamazumi graphs are displayed. They are especially important in customer controls, where the entire assembly process can be monitored in successive sequences. Yamazumi represents a good visualization of individual assembly steps that are well divided into color columns. Applying the method represents the openness of a system that can be continually accessed and altered [8].

As far as the charting process is concerned, the details of the assembly process need to be obtained at the beginning. The best way is to make a video from which you can accurately read the assembly steps times. From the video the information can be processed and a bar graph created [9].

If the assembly stations exceed the specified takt time, line balancing is not properly designed. So we can say that the assembly line exceeds customer demand. Otherwise, operations times must be lower or equal to the takt time.

In this case, the stations must be balancing to reduce the column differences. Perhaps the most obvious layout of charts is that times are the same, they have the same cycle time and are below the tact time limit. In order to unbalance the cycle time on the assembly stations, it is a good choice to change the assembly process and move the individual operations to the assembly stations at which this cycle time is lower. Such a movement is shown in Figure 1 [8].

The balancing process is very complex because it is not easy to improve something that works almost perfectly [10]. In particular, the technology of operations must be respected [11]. Reduction of operation times can be achieved by increasing machine efficiency (faster overclock- ing) to accelerate the molding process (according to available options) or by transferring part of the operations to another assembly station if there is no change in the technological process.

Carrying out the process control and measurement Yamazumi considers the work that does not change the form of the product superfluous. Cycle time can also be reduced in areas where the solution is in electronic systems, for example, in cameras that can capture the storage of parts or their absence [12]. To optimize and balancing process, we need to know a few key factors [13], namely:

- individual assembly operations and their times,

- tact time,

- target cycle time,

- cycle time.

In order to obtain accurate cycle time, time measurements are taken at the assembly stations from the beginning to the end of the assembly process.

Tact time is the principle that all activity within a business is synchronized by a pulse, set by the customer demand [1]. Takt time determines the pulse of the Production System which is the pace of sales, links production activity to actual customer demand, and ensures all the production activity will be synchronized from first process to final assembly process. Takt time refers to the frequency of a part or component must be produced to meet customers' demand [14]. Takt time depends on monthly production demand, if the demand increases the Takt time decreases, if the demand decreases the Takt time increases which mean the output interval increases or decreases.

Tact time relates the customer demand to the time available. This time is a key factor for the customer. Tact time indicates to what extent the supplier is able to deliver the required amount of gears to the customer. Tact time can also indicate the rate at which a customer takes the product of the company. Takt time can be obtained by using the following formula:

$$
T T=\frac{\text { Net available working time per day }}{\text { Total daily customer request }}
$$

Monden et al. [15] suggested that the consideration of task time variability is due to human factors or various disruptions which leads to Uline balancing problem. The task time variability is mainly due to the instability of humans with respect to work rate, skill and motivation as well as the failure sensitivity of complex processes. Becker et al. [3] and Chiang et al. [16] suggested 
task itself a sources of variability and explains the worker performing the task, and the environment where the task is performed. These sources of variability are controlled by minimizing the moving cost of men and machine. Man-machine flexibility is achieved through free flow of material and information in the manufacturing process [15].

Target cycle time - The production capacity of the line indicates the time at which the finished product will be output at the output from the line.

$$
T C T=\frac{\text { Net available working time per day }}{\text { Production capacity of line per day }}
$$

For the calculation above, the net working time per day and the number of gear units per day are required. The optimization goal is to match the cycle time to the target time of the cycle while the target cycle time must not be exceeded. By focusing on these times, we can avoid the formation of bottlenecks on the assembly line.

\section{CASE STUDY}

When analyzing the working time in the selected company, it was found that 12 - hour shifts were made on the assembly line. During these, the operator has a 30 minute break for lunch during a shift. After deducting breaks, the net available working time per day is 23 hours. In minutes, it's about 1380 minutes. The number of pieces produced per day was found by a professional consultant. These data can be input into the TT and TCT calculation.

$$
\begin{gathered}
\text { TT }=\frac{1380 \mathrm{~min}}{1146 \text { units }}=1,2 \mathrm{~min} \\
\mathrm{TCT}=\frac{1380 \mathrm{~min} .}{345000 \text { units }: 301 \text { days }}=1,2 \cdot 0,8=\sim 0,96 \mathrm{~min} .
\end{gathered}
$$

Coefficient 0,8 is lower limit for the annual production line capacity $(80 \%)$.

The TCT calculation is used in the Yamazumi charts as the upper limit. After the assembly line analysis, three assembly stations were selected, with longer cycle times exceeding TCT. Yamazumi charts were created for these stations. Table 1 shows the measured times at the assembly stations.

Table 1. Measured times at selected workplaces

\begin{tabular}{|c|c|c|c|}
\hline & Workplace 1 (OP. 410) & Workplace 2 (OP. 520) & Workplace 3 (OP. 600) \\
\hline VA - added value & $0: 24: 07$ & $0: 44: 00$ & $0: 42: 17$ \\
\hline $\begin{array}{c}\text { NVA - work without added } \\
\text { value }\end{array}$ & $0: 07: 00$ & $0: 03: 00$ & $0: 03: 00$ \\
\hline NW - necessary work & $0: 29: 00$ & $0: 18: 04$ & $0: 20: 07$ \\
\hline Summary & $0: 60: 07$ & $1: 05: 04$ & $1: 05: 24$ \\
\hline
\end{tabular}

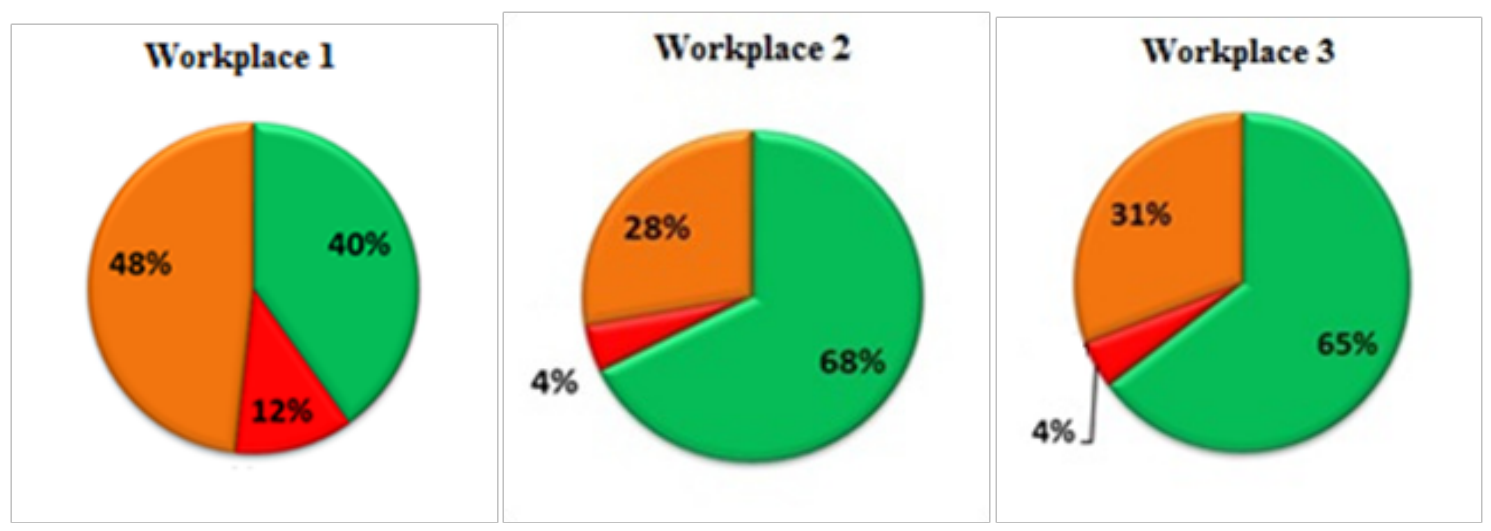

Fig. 2. Percent share of activities on selected workplaces 


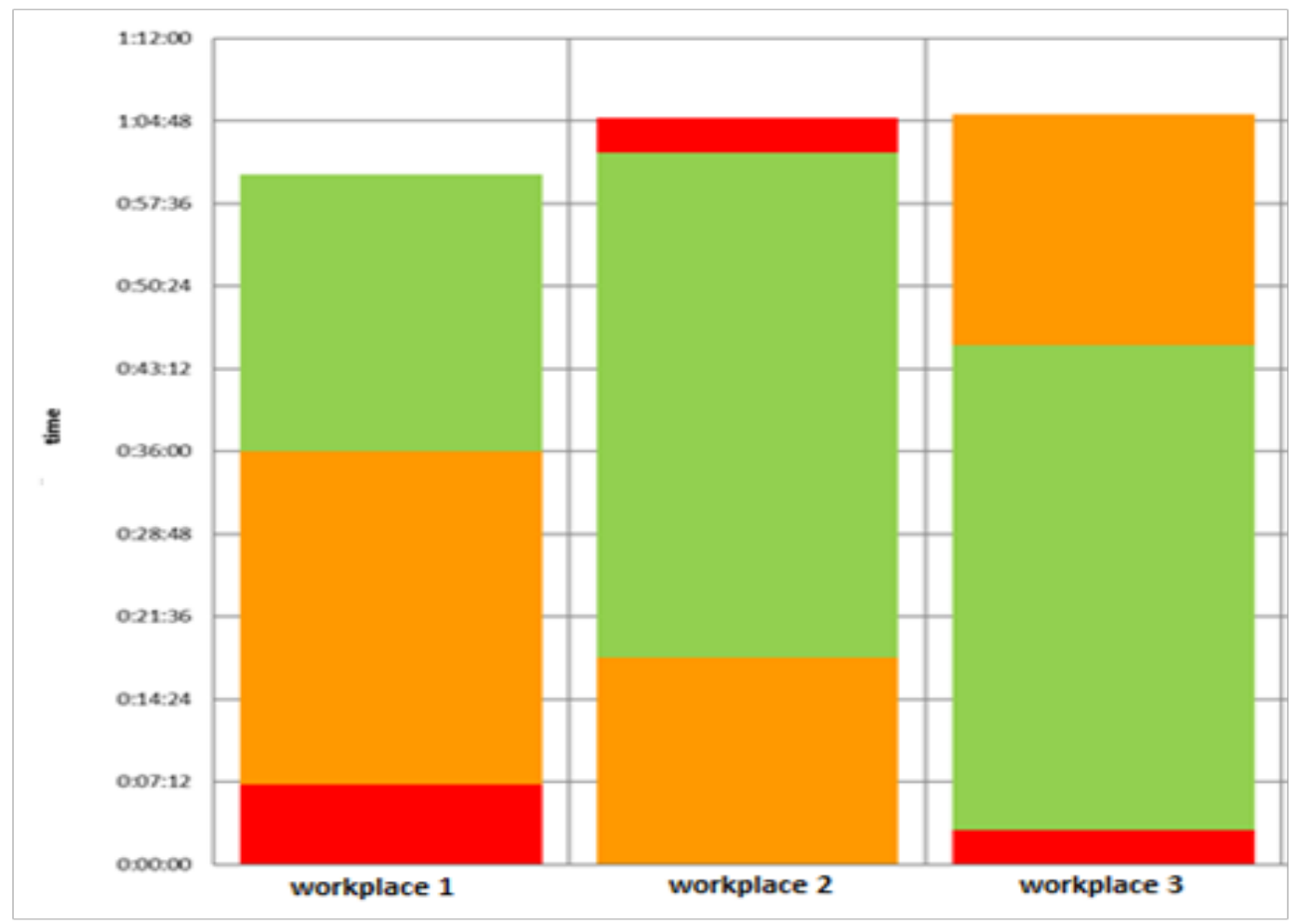

Fig. 3. Actual status of TCT on selected assembly stations

VA added value (green colour) - is value-added work, work that changes shape and product properties.

NW necessary work (orange colour) - is a work that is always done and does not yield any value. This work must be done to alter the shape, value, and performance of the product.

NVA work without added value (red colour) is work without added value. It does not change the form and properties of the product, it is the work that has the lowest value in the Yamazumi graph.

Using backgrounds, the times measured were divided into color spheres according to the Yamazumi method, which represent neutral, added and loss values. These times were simultaneously inserted into the graphs, which are shown in Figure 2. Higher in percentages based on the share of individual activities in the total TCT. The following graph (Figure 3) shows the red limit representing the calculated TCT. In order for the assembly stations to meet the production capacity, their times must be below this red limit.

\section{Kaizen activities - Balancing of assembly lines}

Operation 410 is a manual operation where pre-assembly of the output shaft is performed.
The figure shows the operator performing the preassembly of the output shaft into the gear box by pressing.

The operator deploys a gear that is prepressed together with the needle bearing on the output shaft. Press the keys that are placed under the counter to activate the press with both hands. Then a further series of two-sided presses follows: the lock ring along with the guide, the inner bearing, and finally the plugs. All these operations were recorded in the Yamazumi chart, where it is seen that the initial state cycle slightly exceeds TCT.

The first proposed measure is the elimination of two-handed presses, as this compression system does not allow the operator to perform further work. The operator will not have to hold his hands on the buttons, but only push in a separate button to be added to the position shown in Figure 4. The press starts automatically and therefore has free hands for further operations. The speed of pressing is also increased. During compression, the operator may perform additional operations having an added value e.g. supplement the material.

There was also a reduction in time for operations that do not add any value (about $-1 \mathrm{sec}$.) After re-measuring the resulting cycle time, it was 


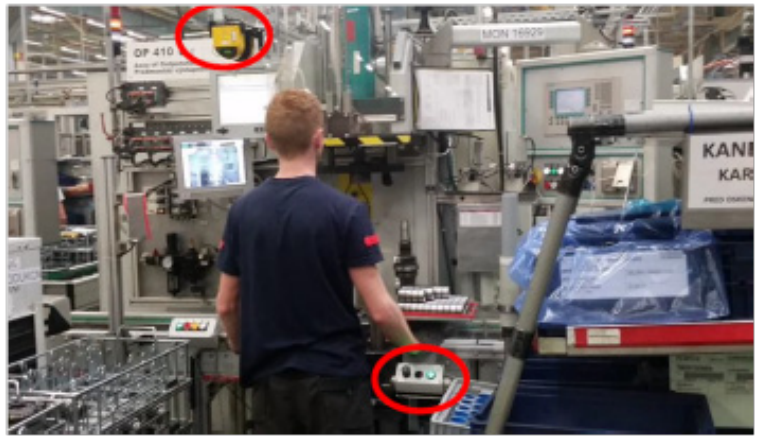

Fig. 4. View on the assembly station (410)

reduced from $61 \mathrm{sec}$. at $47 \mathrm{sec}$. which is under the TCT limit even for a few seconds.

The optimization of this station also includes the installation of a new security system, since the two-sided pressing was a safety standard. The new laser scanner system detects operator movements. One of the main features is motion detection at an angle of up to $270^{\circ}$, while the maximum scanner range is $10 \mathrm{~m}$ from the center. The principle is that the scanner creates a light barrier around the press, which is active just when the press is turned on. As the operator suddenly exceeds this barrier, the scanner records it and stops stamping in one second to prevent any accidents.

At operation 520, the operator presses the bearing cup (F) and 4 cylinders. As shown in Figure 5, the operator inserts these components into the press. After pressing the button, the press automatically molds the cup and 4 cylinders into a gearbox. It takes about 44 seconds after measuring. In addition to pressing, the operator can perform other tasks such as, replacement of empty pallet for full, visual inspection of sleeve (differential case for $4 \times 4$ ) and others. Due to an increase

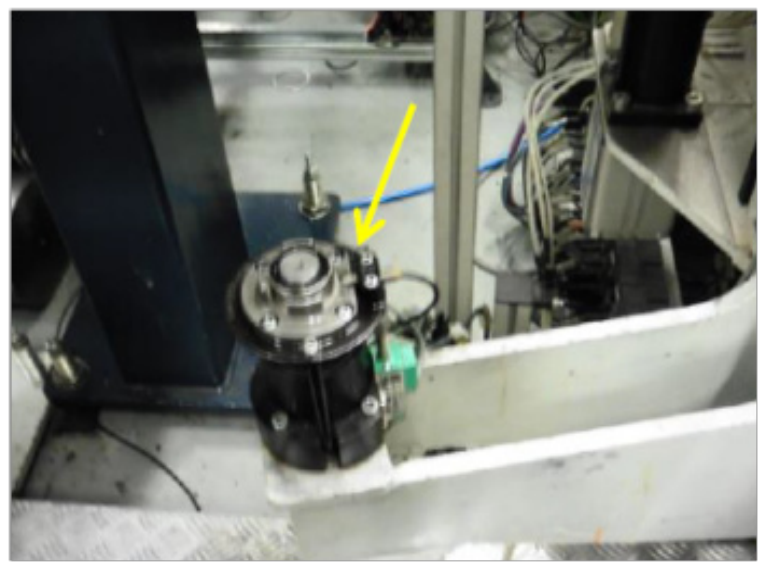

Fig. 6. Inserted bearing on the press head

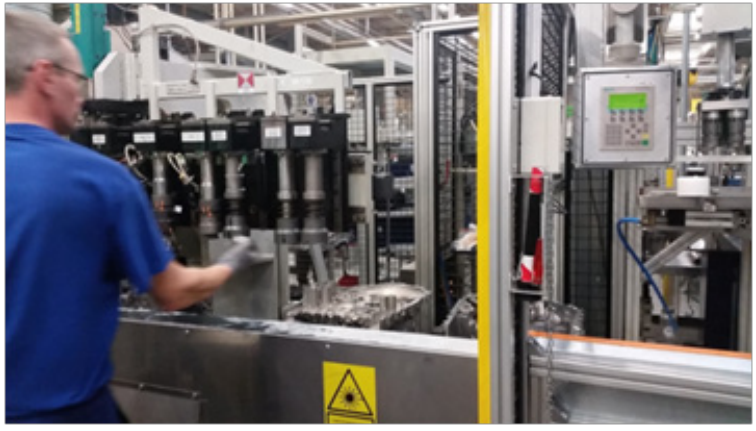

Fig. 5. Aassembly station (520)

in production capacity for 2017, the assembly operation does not meet the required TCT that has been reduced.

The components are pressed sequentially. In order to reduce the time of the assembly station, it has been proposed to remove a certain part of the molded components since at this work station the speed of the press can not be changed. The design is that 1 cylinder is removed from this station and moved to the 480 station that will be created later. They also accelerate neutral operations that do not add value by about $-7 \mathrm{sec}$. After recording the current worksheet chart, it is clear that the operation far exceeds the TCT limit.

The main change is in the red circle so 1 cylinder will be taken to the second station. Onecylinder transfer takes one quarter of the pressing time instead of 44 seconds, only 33 seconds. In addition to the other options and tests, the startup times were reduced from 18 to 11 seconds. After re-recorded on the graph, the resulting time is below the TCT limit. This reduction in time also has the advantage that the operation following the op. 520 now has the same time with a deviation of

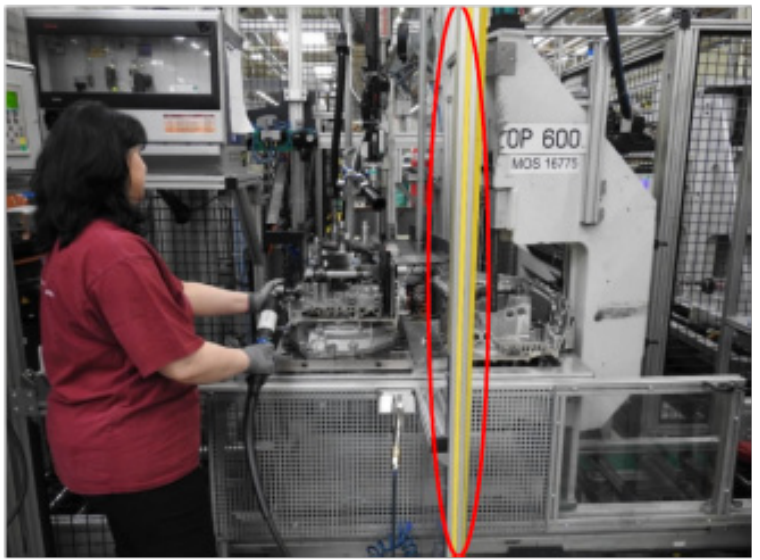

Fig. 7. Assembly station (op. 600) 


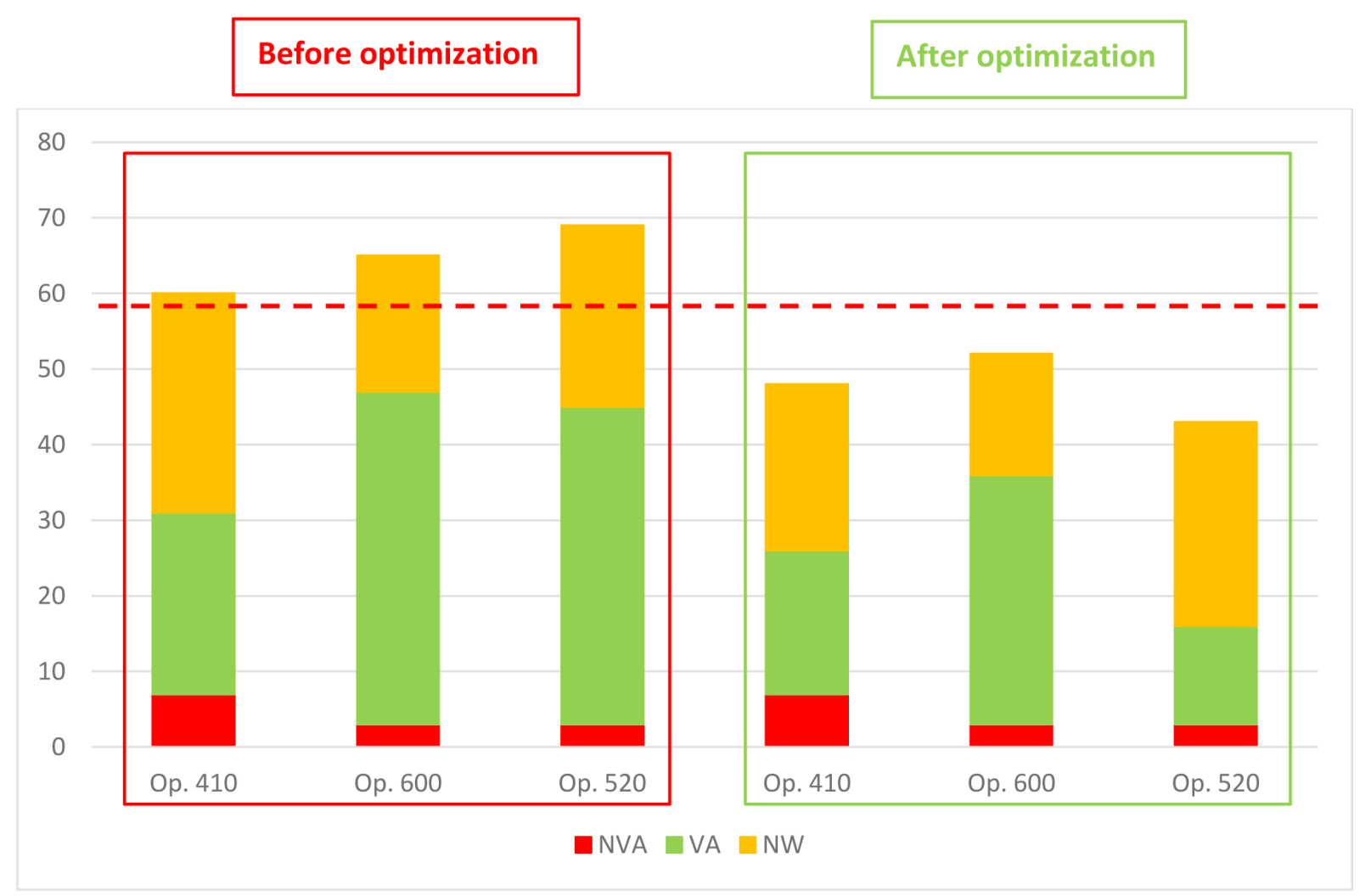

Fig. 8. Target cycle time of assembly stations before and after design and application of changes

about 2 - $3 \mathrm{sec}$. This ensures smoother operation in this part of the assembly line.

At Operation 600, the operator was not trying to keep pace with the subway station where the waiting time was high, this operation was divided into two parts. This decomposition is shown in the picture below in the red circle. After the new operator performs half of the work (screwing) on the left side and on the right side only puts the bearing on the presser head and the green button starts the pressing process (Figure 7 and 6).

The benefit of this change is that the auxiliary automatic press can press the bearing in about 16 seconds. And next to it the operator screws the shaft holder bolts. After measuring, it takes about 9 seconds.

Additional added value actions have been added to hide the remaining time. The zone before the press machine monitors the same safety system as op. 410. The last proposal will be to move operations that take place at the end of assembly at this station where the support and the pin of the parking mechanism are bolted. These operations will be moved to a newly installed assembly station (op.500) which will be semi-automatic (saving 1 operator). This optimization results in a new assembly station time that has been reduced from 65 seconds to 41 seconds and elimination of a tight spot in this mounting section.

\section{RESULTS AND EVALUATION OF CHANGES}

After making all the changes, it can be stated that the Yamazumi tool is the ideal method for increasing labor productivity. The resulting characteristics of the proposed changes have greatly helped reduce assembly station times.

The aim of the project was to find viable solutions that would lead to increased efficiency of the assembly of gearboxes in defined circuits that were created in the analytical part. With regard to this problematic circuit, possible improvements in the continuity of the assembly stations have been identified.

In Figure 8 the graph shows the original times of the three mounting stations in the red box and next to the new times after the optimization of the assembly stations. The three stations were considered bottlenecks in production. Based on the results obtained from the Yamazumi graphs, it was suggested to cancel the two-sided press and to turn it into automatic without direct intervention of the operator. This change will bring: 
- elimination of a bottlenecks of assembly line,

- improving the efficiency of the operator's work,

- increase the content of added values.

Another proposal was to divide one assembly station into two parts, where the operator previously performed all the operations manually. At present it is a semi-automatic assembly station where the operator assists the press robot and thus takes part of his work. This change will bring:

- significant reduction in the time of the assembly station,

- additional added values,

- improving the efficiency of the operator's work,

- time alignment with the next assembly station.

Part of the proposals is to shorten the time of neutral activities, after testing the operator putting them into practice, translating part of the work from one assembly station to another without changing the technological process of production.

\section{CONCLUSION}

The contribution is dedicated to the area of the assembly line, its optimization in the chosen enterprise of the automotive supply sector. On the basis of the analyzes carried out at the assembly stations, changes have been proposed to improve the flow of gearboxes to a narrow spot and to accelerate the continuous production time.

The assembly line analysis using the Yamazumi method was 3 assembly stations where bottleneck and insufficient performance to fill the production capacity was identified. Elimination of deficiencies could lead to an acceleration of the production run time.

In the project part, the problem of the assembly stations and the design of the slimming operations were defined. In the first phase, a table of measured times at the assembly stations was drawn up and the Yamazumi charts in their original form with a designated target time limit for the assembly operations. After the design changes, new Yamazumi charts were created to compare the original statuses. The assembly line optimization was completed by a slight reduction in neutral activity times.

The result of the project has achieved the stated goal of accelerating and streamlining the production process, improving the stability of the assembly process, and consequently increasing the annual profit and increasing the rewards for employees.

\section{Acknowledgements}

This contribution is the result of the projects VEGA 1/0403/18, VEGA 1/0063/16, VEGA 1/0708/16, KEGA 018TUKE-4/2016.

\section{REFERENCES}

1. Rahani A.R. and Al-Asyraf M. Production Flow Analysis through Value Steam Mapping: A Lean Manufacturing Process Case Study. International Symposium on Robotic and Intelligent Sensors 41, 2012, 1727-1734.

2. Melton. T. The Benefit of Lean Manufacturing: What Lean Thinking has to Offer the Process Industries. Chemical Engineering Research and Design 83, 2005, 662-673.

3. Becker C. and Scholl A. Survey on problems and methods in generalized assembly line balancing. European Journal of Operational Research 168, 2006, 694-715.

4. Agpak K. and Gokcen H. Assembly line balancing: Two resource constrained cases. International Journal of Production Economics 96, 2005, 129-140.

5. Lumnitzer E., Liptai P. and Drahos R. Measurement and Assessment of Pulsed Magnetic Fields in the Working Environment. In: 8th International Scientific Symposium on Electrical Power Engineering (Elektroenergetika). 2015, 331-333.

6. Adnan A.N., Jaffar A., Yusoff N. and Halim A. Implementation of Continuous Flow System in Manufacturing Operation. Applied Mechanics and Materials 393, 2014, 9-14.

7. Adnan A.N., Ain Arbaai N. and Ismail A. Improvement of overall efficiency of production line by using line balancing. ARPN Journal of Engineering and Applied Sciences 11, 2016, 7752-7758.

8. Semjon V. and Evin. E. Increasing the productivity of the assembly line by balancing of assembly stations using the Yamazumi method. Transfer Inovácií 13, 2009, 73-77.

9. Mantič M., Kul'ka J., Krajňák J., Kopas M. and Schneider M. Influence of selected digitization methods on final accuracy of 3D model. Production Management and Engineering Sciences. 2016, 475-480.

10. Debski H., Teter A., Kubiak T. and Samborski S. Local buckling, post-buckling and collapse of thin-walled channel section composite columns subjected to quasi-static compression. Composite structures 136, 2016, 593-601.

11. Garbacz T., Jachowicz T. and Tor-Swiatek A. The effect of blowing agents on the effectiveness of poly(vinyl chloride) extrusion. Advances in Science and Technology-Research Journal 10, 2016, 217-223. 
12. Kral J. and Kral J. Verification of manufacturing accuracy of mathematically defined shaped surfaces on 3D CNC milling machine. Key Engineering Materials 581, 2014, 423-430.

13. Mircetic D., Nikolicic S., Stojanovic D. and Maslaric M. Modified top down approach for hierarchical forecasting in a beverage supply chain. Transportation Research Procedia 22, 2017, 193-202.

14. Strohmandl J., Tomek M., Šafařík Z. and Málek Z. SW To Support the Project Management of Conveyor Design and Installation. Vision 2020: Inno- vation Management, Development Sustainability, and Competitive Economic Growth - Proceedings of the 28th International Business Information Management Association Conference, IBIMA 2016. pp. 2448-2453, 2016.

15. Monden Y. Toyota Production System. Industrial Engineering and Management Press, Norcross, GA, 1998.

16. Chiang W.Ch. and Urban T.L. The stochastic Uline balancing problem: A heuristic procedure. European Journal of Operational Research 2006, 1767-1781. 